\title{
Structural Determination of Neutral O-linked Oligosaccharide Alditols by Negative Ion LC-Electrospray-MS
}

\author{
Niclas G. Karlsson, Benjamin L. Schulz, and Nicolle H. Packer \\ Proteome Systems Ltd., Sydney, Australia
}

\begin{abstract}
Neutral O-linked oligosaccharides released from the salivary mucin MUC5B were separated and detected by negative ion LC-MS and LC-MS ${ }^{2}$. The resolution of the chromatography and the information obtained from collision induced dissociation of detected $[\mathrm{M}-\mathrm{H}]^{-}$ions were usually sufficient to identify the sequence of individual oligosaccharides, illustrated by the fact that 50 different oligosaccharides ranging from disaccharides to nonasaccharides could be assigned from the sample. Fragmentation was shown to yield mostly reducing end sequence fragments $\left(Z_{i}\right.$ and $\left.Y_{i}\right)$, enabling primary sequence assignment. Specific fragmentation pathways or patterns were also detected giving specific linkage information. The reducing end core (Gal/GlcNAc $\beta 1$-3GalNAcol or Gal/GlcNAc $\beta 1-3(G l c N A c \beta 1-6)$ GalNAcol) could be deduced from the pronounced glycosidic $\mathrm{C}-3$ cleavage and $\mathrm{A}_{i}$ type cleavages of the reducing end GalNAcol, together with the non reducing end fragment from the loss of a single substituted GalNAcol. Substitution patterns on GlcNAc residues were also found, indicative for C-4 substitution $\left({ }^{0,2} \mathrm{~A}_{i}-\mathrm{H}_{2} \mathrm{O}\right.$ cleavage $)$ and disubstitution of $\mathrm{C}-3$ and $\mathrm{C}-4\left(\mathrm{Z}_{i} / \mathrm{Z}_{i}\right.$ cleavages). This kind of fragmentation can be used for assigning the mode of chain elongation (Gal $\beta 1-3 /$ 4GlcNAc $31-$ ) and identification of Lewis type antigens like Lewis $a / x$ and Lewis $b / y$ on O-linked oligosaccharides. In essence, negative ion LC-MS ${ }^{2}$ was able to generate extensive data for understanding the overall glycosylation pattern of a sample, especially when only a limited amount of material is available. (J Am Soc Mass Spectrom 2004, 15, 659-672) (c) 2004 American Society for Mass Spectrometry
\end{abstract}

$\mathrm{I}$

dentification and understanding of biological processes involving glycoconjugates is a scientific area of increasing interest. This increase in interest has worked hand in hand with the development of more sensitive and specific analytical techniques in this field. Mass spectrometry has been the detection and characterization tool most frequently used in recent years for analysis of glycoproteins, glycopeptides, glycolipids, or free oligosaccharides (some reviews in [1-5]). In principle, mass spectrometry suffers from the fact that the monomeric components (the monosaccharides) of oligosaccharide chains consist of isomeric building blocks, and that linkage configuration and position are difficult to obtain with the technique. Even so, researchers have applied mass spectrometric techniques to answer biological questions (some examples in [6-9]).

Characterization of released or free oligosaccharides by mass spectrometry using electrospray ionization in negative mode has recently been shown to give both sequence and linkage information [10,11]. Negative ion mode has been shown to be applicable to both nega-

Published online February 27, 2004

Address reprint requests to Dr. N. G. Karlsson, Proteome Systems Ltd., locked bag 2073, North Ryde, Sydney, NSW 1670, Australia. E-mail: niclas.karlsson@proteomesystems.com tively charged oligosaccharides and for neutral oligosaccharides [12-14], and offers high sensitivity of detection without requiring derivatization or adduct formation to aid ionization. Electrospray is also easily coupled to with high resolution liquid chromatography, an important factor in resolving the degeneracy of structural isomers found in oligosaccharide mixtures.

Mucin-type O-linked oligosaccharides are found linked to serine and threonine via a GalNAca1-linkage. These amino acids are often found as clustered domains in the protein backbone, which leads to a high potential for interaction through the subsequently closely spaced oligosaccharides. For example, the ligands for E-, L-, and P-selectin have all been shown to interact via their clustered domains of sialylated and/or sulfated Olinked oligosaccharides (reviewed in [15, 16]). A rich source of O-linked oligosaccharides is the mucin proteins found associated with cell membranes or secreted from cells localized to mucosal surfaces [17]. Here, mucins interact in the initial phase of microbial invasion by exposing a wide variety of oligosaccharide epitopes targeted towards microbial adhesins [18-20].

Isolation and full characterization of mucin oligosaccharides usually requires several steps of isolation of both mucin components and individual oligosaccharides, followed by analytical techniques like ${ }^{1} \mathrm{H}-\mathrm{HMR}$, 
requiring nanomoles of material. As part of an aim to simplify and cut this process short, we decided to find out how much information could be obtained by the more sensitive technique of negative ion $\mathrm{MS}^{2}$ in an ion trap on-line with liquid chromatography using graphitized carbon as stationary phase. O-linked oligosaccharides are traditionally released from the protein core by reductive $\beta$-elimination. This procedure converts the reducing end GalNAc into its alditol. Further derivatization of the reducing end is thus made impossible, and techniques, which have been developed for analysis of reducing sugars by addition of a charged group in order to promote ionization in mass spectrometry, cannot be used. However, negative ion mode electrospray mass spectrometry of oligosaccharide alditols circumvents the need for derivatization. Since information about fragmentation of oligosaccharide alditols using negative ion collision induced dissociation is scarce, there is a need to establish its usefulness for structural characterization. Due to the absence of good commercial standards of O-linked oligosaccharides, we decided to isolate mucin oligosaccharides from easily available mucin sources that express a wide variety of oligosaccharide epitopes. This allowed us to draw general conclusions about how oligosaccharide alditols fragment. In this report we describe the negative ion mode ES-MS $^{2}$ fragmentation of neutral oligosaccharides mainly isolated from the well characterized human salivary MUC5B oligosaccharides [21].

\section{Experimental}

\section{Isolation of Salivary MUC5B Mucins}

Saliva (5-10 ml) from blood group H, blood group A/B, and blood group A individuals was collected, reduced and alkylated as described previously [14], and high molecular mass proteins were collected after concentrating the samples to $500-1000 \mu \mathrm{L}$ in an Ultrafree- 4 centrifugal filter (50 kDa cut off) (Millipore, Bedford, MA). The high molecular mass fraction from each individual was then loaded onto a preparative SDSpolyacrylamide/agarose composite gel [14] without sample wells. The gels were run, electroblotted and stained with Alcian blue, and oligosaccharides were released from the broad MUC5B containing band by reductive $\beta$-elimination as described [14].

\section{Preparation of Oligosaccharides for $L C-M S^{2}$}

Oligosaccharides from porcine gastric mucins $(1.0 \mathrm{mg})$ (Sigma-Aldrich, St Louis, MO), rat intestinal Muc2 (1.0 $\mathrm{mg}$ ) [22], and human salivary MUC5B were released in $1.0 \mathrm{~mL}$ of $0.5 \mathrm{M} \mathrm{NaBH}_{4}$ or $\mathrm{NaBD}_{4}$, both in $50 \mathrm{mM}$ $\mathrm{NaOH}$. Samples were desalted with $1.0 \mathrm{~mL}$ of AG50W $\times 2$ cation exchange beads (Bio-Rad, Hercules, CA) packed in a $1.0 \mathrm{~mL}$ Strata C18-E cartridge (Phenomenex, Torrance, CA), and the oligosaccharides were eluted with $10 \mathrm{~mL}$ of water and lyophilized. Borate complexes were removed with repeated (5 times) addition of $1 \%$ acetic acid in methanol (100 $\mu \mathrm{L}$ each time), followed by vacuum centrifugation. Remaining oligosaccharides were dissolved in $1.0 \mathrm{~mL}$ of water. Neutral human salivary and rat intestinal oligosaccharides $(50 \mu \mathrm{L}$ of each) were separated from the acidic oligosaccharides by passage through $10 \mu \mathrm{L}$ of DEAE-Sephadex ( $\mathrm{Ac}^{-}$ form) (Amersham Biosciences, Uppsala, Sweden) packed on top of a C18 Zip-tip (Millipore). Samples were eluted with $200 \mu \mathrm{L}$ of water, dried and redissolved in $50 \mu \mathrm{L}$ of water and subjected to $\mathrm{LC}^{-\mathrm{MS}^{2}}$, or to direct infusion $\mathrm{MS}^{\mathrm{n}}$.

\section{$M S^{n}$ and $L C-M S^{2}$ of Oligosaccharides}

Direct infusion (50-250 $\mu \mathrm{L}$ of $40 \%$ acetonitrile/10 mM ammonium bicarbonate with a flow of $10-50 \mu \mathrm{L} / \mathrm{min}$ ) was carried out of oligosaccharides released from an equivalent of $0.1 \mathrm{mg}$ mucin/mL. Mass spectra were recorded in negative ion mode with a LCQ Deca XP ESI-ion trap (ThermoFinnigan, San Jose, CA). Collisions for $\mathrm{MS}^{2}$ and $\mathrm{MS}^{3}$ were carried out with an isolation window of $3.0 \mathrm{u}$, a normalized collision energy of $40 \%$, and an activation time of $30 \mathrm{~ms}$. Oligosaccharides (10 $\mu \mathrm{L}$ of sample) were also analyzed by $\mathrm{LC}^{-\mathrm{MS}^{2}}$ as described [14] using a graphitized carbon column $(150 \times$ $0.32 \mathrm{~mm}$ ) (Thermo Hypersil-Keystone, Runcorn, UK), containing $5 \mu \mathrm{m}$ Hypercarb particles. Oligosaccharides were eluted using a linear gradient from $0-25 \%$ acetonitrile ( $25 \mathrm{~min}$ ) in $10 \mathrm{mM}$ ammonium bicarbonate with a flow rate of $6-10 \mu \mathrm{L} / \mathrm{min}$ and detected in the mass spectrometer by full scan (mass range $m / z$ 320-2000) followed by 1-4 dependent $\mathrm{MS}^{2}$ scans of the 1-4 most intense ions.

\section{Results and Discussion}

\section{LC-MS of Neutral Oligosaccharide Aalditols by HPLC Using Graphitized Carbon}

The base source of neutral oligosaccharides was MUC5B isolated from saliva of a blood group $\mathrm{O}, \mathrm{Le}^{\mathrm{a}-\mathrm{b}+}$ secretor by gel electrophoresis on composite agarose/ polyacrylamide gradient gels, but other sources were also used to obtain a range of oligosaccharide structures (Table 1). Neutral oligosaccharides from MUC5B analysed by LC-MS (Figure 1) were detected mostly as [M $\mathrm{H}]^{-}$ions and were eluted between 5-25 $\mathrm{min}$ in the chromatogram. The chromatographic resolution of the MUC5B associated oligosaccharides is shown in Figure $1 \mathrm{a}$ and the compositions of the major oligosaccharides detected are shown in Figure 1b. The selectivity of the carbon chromatography column allowed individual oligosaccharide components to be isolated in the ion trap for further collision and structural interpretation. This enabled us to establish fragmentation pathways of neutral oligosaccharide alditols in negative ion mode MS and to identify diagnostic fragmentation patterns of particular oligosaccharide epitopes, such as mucin oli- 
Table 1. Neutral Oligosaccharides detected by LC-MS ${ }^{2}$

\begin{tabular}{|c|c|c|c|c|c|c|}
\hline $\begin{array}{l}{[\mathrm{M}-\mathrm{H}]^{-} \text {ion }} \\
\text { (observed) }\end{array}$ & $\begin{array}{c}\mathrm{RT} \\
(\mathrm{min})\end{array}$ & Deduced sequence & Core & $\begin{array}{l}\text { Chain } \\
\text { type }\end{array}$ & $\begin{array}{l}\text { Lewis } \\
\text { type }\end{array}$ & $\begin{array}{l}\text { Blood } \\
\text { group }\end{array}$ \\
\hline \multicolumn{7}{|c|}{ Salivary MUC5B from blood group $\mathrm{H}$ individual } \\
\hline 384 & 6.4 & Hex -3HexNAcol & 1 & & & \\
\hline 425 & 7.2 & HexNAc-3HexNAcol & 3 & & & \\
\hline 530 & 20.3 & Fuc-Hex-3HexNAcol & 1 & & & $\mathrm{H}$ \\
\hline 587 & 10.6 & $\mathrm{Hex}-3(\mathrm{HexNAc-6}) \mathrm{HexNAcol}{ }^{\mathrm{a}}$ & 2 & & & \\
\hline 587 & 12.5 & Hex-4HexNAc-3HexNAcol & 1 & & & \\
\hline 587 & 12.8 & Hex-3HexNAc-3HexNAcol & 3 & & & \\
\hline 587 & 12.8 & HexNAc-Hex-3HexNAcol & 1 & & & \\
\hline 628 & 11.9 & HexNAc-3(HexNAc-6)HexNAcol & 4 & & & \\
\hline 733 & 9.1 & Hex-3/4(Fuc-3/4)HexNAc-3HexNAcol & 3 & $N A^{b}$ & $a / x$ & \\
\hline 733 & 14.3 & Fuc-Hex-3HexNAc-3HexNAcol & 3 & 1 & & $\mathrm{H}$ \\
\hline 733 & 16.9 & Fuc-Hex-4HexNAc-3HexNAcol & 3 & 2 & & $\mathrm{H}$ \\
\hline 733 & 20.6 & Fuc-Hex-3(HexNAc-6)HexNAcol & 2 & & & $\mathrm{H}$ \\
\hline 749 & 13.7 & Hex-3(Hex-4HexNAc-6)HexNAcol & 2 & 2 & & \\
\hline 749 & 14.2 & Hex-4HexNAc-Hex-3HexNAcol & 1 & 2 & & \\
\hline 790 & 14.3 & HexNAc-3(Hex-4HexNAc-6)HexNAcol & 4 & 2 & & \\
\hline 879 & 13.4 & Fuc-Hex-3/4(Fuc-3/4)HexNAc-3HexNAcol & 3 & NA & $b / y$ & $\mathrm{H}$ \\
\hline 879 & 15.3 & Fuc-Hex-3/4(Fuc-3/4)HexNAc-3HexNAcol & 3 & NA & $b / y$ & $\mathrm{H}$ \\
\hline 895 & 11.9 & Hex-3(Hex-3/4(Fuc-3/4)HexNAc-6)HexNAcol & 2 & NA & $a / x$ & \\
\hline 895 & 14.9 & Hex-3/4(Fuc-3/4)HexNAc-Hex-3HexNAcol & 1 & NA & $a / x$ & \\
\hline 895 & 17.0 & Hex-3(Fuc-Hex-4HexNAc-6)HexNAcol & 2 & 2 & & $\mathbf{H}$ \\
\hline 895 & 20.8 & Fuc-Hex-3(Hex-4HexNAc-6)HexNAcol & 2 & 2 & & $\mathbf{H}$ \\
\hline 936 & 15.3 & Fuc-Hex-3HexNAc-3(HexNAc-6)HexNAcol & 2 & 1 & & $\mathrm{H}$ \\
\hline 936 & 17.5 & HexNAc-3(Fuc-Hex-4HexNAc-6)HexNAcol & 4 & 2 & & $\mathbf{H}$ \\
\hline 952 & 17.2 & Hex-3HexNAc-3(Hex-3HexNAc-6)HexNAcol & 4 & 1,1 & & \\
\hline 1041 & 13.1 & Hex-3/4(Fuc-3/4)HexNAc-(Fuc-)Hex-3HexNAcol & 1 & NA & $a / x$ & \\
\hline 1041 & 14.1 & Fuc-Hex-HexNAc-(Fuc-)Hex-3HexNAcol & 1 & NA & & $\mathrm{H}$ \\
\hline 1041 & 15.5 & Fuc-Hex-3/4(Fuc-3/4)HexNAc-Hex-3HexNAcol & 1 & NA & $\mathrm{b} / \mathrm{y}$ & $\mathrm{H}$ \\
\hline 1041 & 20.7 & Fuc-Hex-3(Fuc-Hex-3HexNAc-6)HexNAcol & 2 & 1 & & $\mathrm{H}, \mathbf{H}$ \\
\hline 1041 & 21.9 & Fuc-Hex-3(Fuc-Hex-4HexNAc-6)HexNAcol & 2 & 2 & & $\mathrm{H}, \mathbf{H}$ \\
\hline 1082 & 17.3 & HexNAc-3(Fuc-Hex-3/4(Fuc-3/4)HexNAc-6)HexNAcol & 4 & NA & $b / y$ & H \\
\hline 1098 & 14.6 & Hex-3/4(Fuc-3/4)HexNAc-3(Hex-HexNAc-6)HexNAcol & 4 & NA,NA & $a / x$ & \\
\hline 1098 & 16.2 & Fuc-Hex-3HexNAc-3(Hex-3HexNAc-6)HexNAcol & 4 & 1,1 & & $\mathrm{H}$ \\
\hline 1098 & 18.1 & Hex-4HexNAc-3(Fuc-Hex-4HexNAc-6)HexNAcol & 4 & 2,2 & & $\mathbf{H}$ \\
\hline 1098 & 19.1 & Fuc-Hex-4HexNAc-3(Hex-HexNAc-6)HexNAcol & 4 & 2,NA & & $\mathrm{H}$ \\
\hline 1114 & 16.0 & Hex-HexNAc-(Hex-HexNAc-)Hex-3HexNAcol & 1 & NA,NA & & \\
\hline 1187 & 16.3 & Fuc-Hex-3/4(Fuc-3/4)HexNAc-3(Fuc-)Hex-3HexNAcol & 1 & NA & $\mathrm{b} / \mathrm{y}$ & $\mathrm{H}$ \\
\hline 1187 & 21.9 & Fuc-Hex-3(Fuc-Hex-3/4(Fuc-3/4)HexNAc-6)HexNAcol & 2 & NA & $\mathbf{b} / \mathbf{y}$ & $\mathrm{H}, \mathrm{H}$ \\
\hline 1244 & 17.8 & Hex-HexNAc-3(Fuc-Hex-(Fuc-3/4)HexNAc-6)HexNAcol & 4 & NA,NA & $\mathbf{b} / \mathbf{y}$ & $\mathbf{H}$ \\
\hline 1244 & 18.8 & Fuc-Hex-3HexNAc-6(Fuc-Hex-4HexNAc-6)HexNAcol & 4 & 1,2 & & $\mathrm{H}, \mathbf{H}$ \\
\hline 1244 & 21.7 & Fuc-Hex-4HexNAc-3(Fuc-Hex-4HexNAc-6)HexNAcol & 4 & 2,2 & & $\mathrm{H}, \mathbf{H}$ \\
\hline 1260 & 14.9 & Hex-3/4(Fuc-3/4)HexNAc-(Hex-HexNAc-)Hex-3HexNAcol & 1 & NA,NA & $a / x$ & \\
\hline 1260 & 16.3 & Hex-3/4(Fuc-3/4)HexNAc-(Hex-HexNAc-)Hex-3HexNAcol & 1 & NA,NA & $a / x$ & \\
\hline 1260 & 18.0 & Fuc-Hex-4HexNAc-(Hex-HexNAc-)Hex-3HexNAcol & 1 & 2,NA & & $\mathrm{H}$ \\
\hline 1390 & 18.6 & Fuc-Hex-3HexNAc-3(Fuc-Hex3/4(Fuc-3/4)HexNAc-6)HexNAcol & 4 & $1, \mathbf{N A}$ & $\mathbf{b} / \mathbf{y}$ & $\mathrm{H}, \mathbf{H}$ \\
\hline 1390 & 19.1 & Fuc-Hex-3/4(Fuc-3/4)HexNAc-3(Fuc-Hex-4HexNAc-6)HexNAcol & 4 & NA,2 & $\mathrm{b} / \mathrm{y}$ & $\mathrm{H}, \mathbf{H}$ \\
\hline 1406 & 15.5 & Fuc-Hex-3/4(Fuc-3/4)HexNAc-Hex-3(Hex-HexNAc-6)HexNAcol & 2 & NA,NA & $\mathrm{b} / \mathrm{y}$ & $\mathrm{H}$ \\
\hline 1479 & 17.1 & Hex-HexNAc-(Hex-HexNAc-)Hex-3(Hex-HexNAc-6)HexNAcol & 2 & NA, NA, NA & & \\
\hline 1552 & 18.8 & Hex-3/4(Fuc-3/4)HexNAc-(Fuc-Hex-3/4(Fuc-3/4)HexNAc-)Hex-3HexNAcol & 1 & NA,NA & $a / x, b / y$ & $\mathrm{H}$ \\
\hline 1625 & 18.3 & Hex-3/4(Fuc-3/4)HexNAc-(Hex-HexNAc-)Hex-3(Hex-HexNAc-6)HexNAcol & 2 & NA,NA,NA & $\mathrm{a} / \mathrm{x}$ & \\
\hline 1625 & 18.3 & Hex-3/4(Fuc-3/4)HexNAc-Hex-HexNAc-Hex-3(Hex-HexNAc-6)HexNAcol & 2 & NA & $a / x$ & \\
\hline \multicolumn{7}{|c|}{ Salivary MUC5B from blood group A individual } \\
\hline 1390 & & Fuc-Hex-3(Fuc-(HexNAc-)Hex-3/4(Fuc-3/4)HexNAc-6)HexNAcol & 2 & NA & $\mathbf{b} / \mathbf{y}$ & $\mathrm{H}, \mathbf{A}$ \\
\hline \multicolumn{7}{|c|}{ Salivary MUC5B from blood group A/B individual } \\
\hline 1349 & & Fuc-Hex-3(Fuc-(Hex-)Hex-3/4(Fuc-3/4)HexNAc-6)HexNAcol & 2 & NA & $\mathbf{b} / \mathbf{y}$ & $\mathrm{H}, \mathbf{B}$ \\
\hline \multicolumn{7}{|c|}{ Rat intestinal Muc2 } \\
\hline 1041 & & Fuc-Hex-3(Fuc-Hex-4HexNAc-6) HexNAcol & 2 & 2 & & $\mathrm{H}, \mathbf{H}$ \\
\hline \multicolumn{7}{|c|}{ Porcine gastic mucins } \\
\hline 530 & & Fuc-Hex-3HexNAcol & 1 & & & $\mathrm{H}$ \\
\hline 733 & & Fuc-(HexNAc-)Hex-3HexNAcol & 1 & & & A \\
\hline
\end{tabular}

a Bold letters indicate the C-6 branch of the HexNAcol.

'NA means not assigned. 

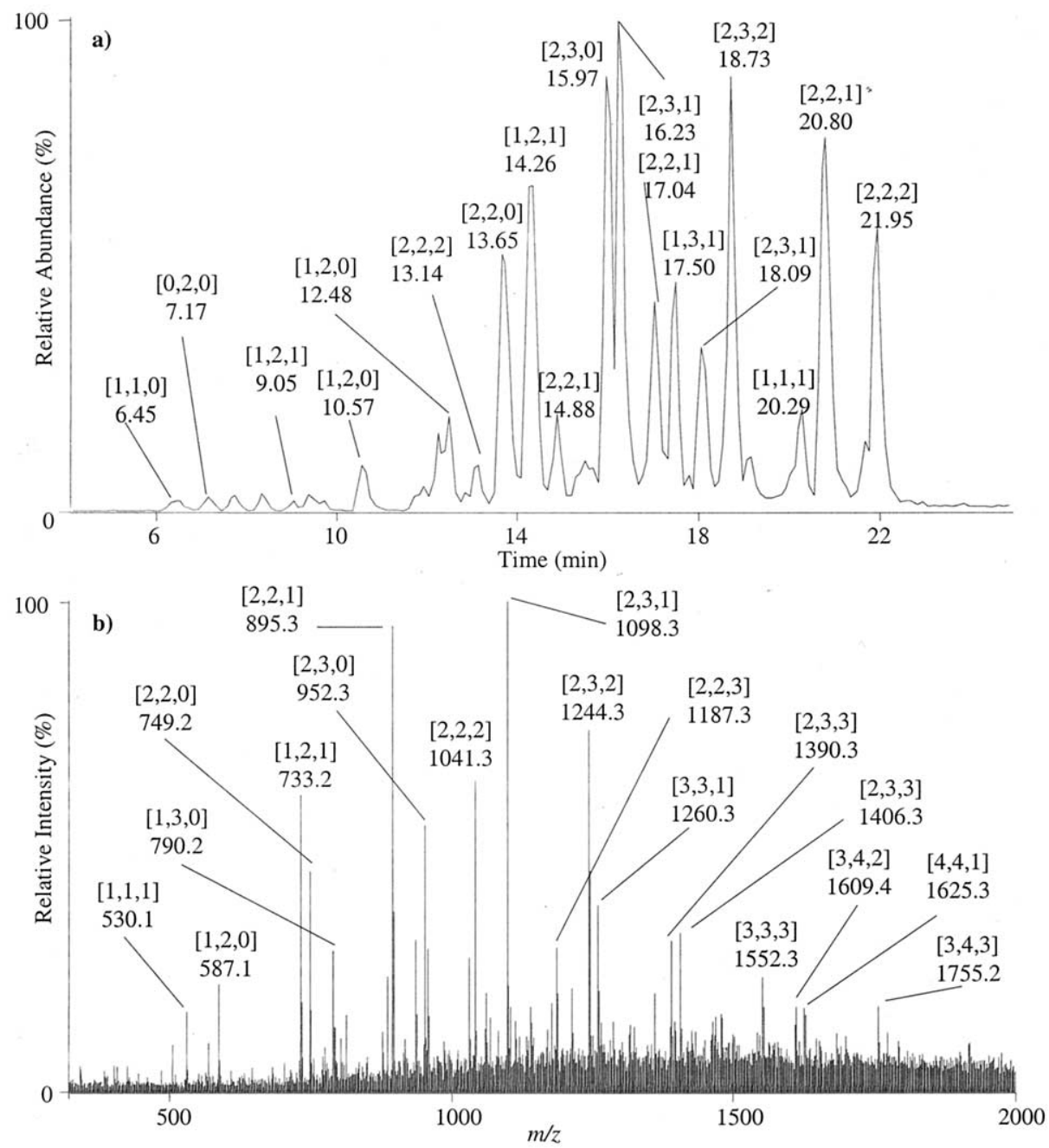

Figure 1. LC-MS of neutral MUC5B mucin oligosaccharide alditols. (a) shows the base peak chromatogram where the major composition in each peak is labeled and (b) shows a composite spectrum showing the combined spectra acquired between 5-25 min. Compositions are assigned as [Hex,HexNAc,dHex], including the reducing end GalNAcol as HexNAc.

gosaccharide core type, $\mathrm{N}$-acetyllactosamine configuration, and blood group related epitopes like $\mathrm{ABO}$ and Lewis like epitopes. The molecular bases of these epitopes are described in Table 2.

\section{Fragmentation of $[\mathrm{M}-\mathrm{H}]^{-}$Ions of Neutral Mucin Oligosaccharide Alditols}

The ability to obtain specific sequence information by fragmentation of oligosaccharides requires not only detection of sequence specific fragment ions, but also that information about linkage position and configuration is obtain. While fragmentation with mass spectrometry may not be the optimal method to obtain this information, its sensitivity and capacity for automation makes the technique very attractive as a first approach for structural characterization. In Figure 2, $\mathrm{MS}^{2}$ fragment ion spectra of five different isomers with the
Table 2. Oligosaccharide epitopes on mucin oligosaccharides

\begin{tabular}{|c|c|}
\hline Epitope & Structure \\
\hline \multicolumn{2}{|l|}{ Core type } \\
\hline Core 1 & Gal $\beta 1-3 G$ alNAc \\
\hline Core 2 & Gal $\beta 1-3$ (GIcNAc $\beta 1-6)$ GalNAc \\
\hline Core 3 & GIcNAc $\beta 1-3 G a I N A c$ \\
\hline Core 4 & GlcNAc $\beta 1-3(G I c N A c \beta 1-6)$ GalNAc \\
\hline \multicolumn{2}{|c|}{$\mathrm{N}$-Acetyllactosamine elongation type } \\
\hline Type 1 & -Gal $\beta 1-3 \mathrm{GIcNAc} \beta 1-$ \\
\hline Type 2 & -Gal $\beta 1-4 G I c N A c \beta 1-$ \\
\hline \multicolumn{2}{|c|}{ Terminal structures } \\
\hline Lewis a & Gal $\beta 1-3($ Fuc $\alpha 1-4)$ GIcNAc $\beta 1-$ \\
\hline Lewis b & Fuc $\alpha 1-2 \mathrm{Gal} \beta 1-3$ (Fuc $\alpha 1-4$ )GlcNAc $\beta 1-$ \\
\hline Lewis $\mathrm{x}$ & Gal $\beta 1-4($ Fuc $\alpha 1-3)$ GlcNAc $\beta 1-$ \\
\hline Lewis y & Fuc $\alpha 1-2 \mathrm{Gal} \beta 1-4($ Fuc $\alpha 1-3) \mathrm{GlcNAc} \beta 1-$ \\
\hline Blood group $\mathrm{H}$ & Fuc $\alpha 1-2 \mathrm{Gal} \beta 1-$ \\
\hline Blood group A & Fuc $\alpha 1-2($ GalNAc $\alpha 1-3)$ Gal $\beta 1-$ \\
\hline Blood group $B$ & Fuc $\alpha 1-2($ Gal $\alpha 1-3)$ Gal $\beta 1-$ \\
\hline
\end{tabular}



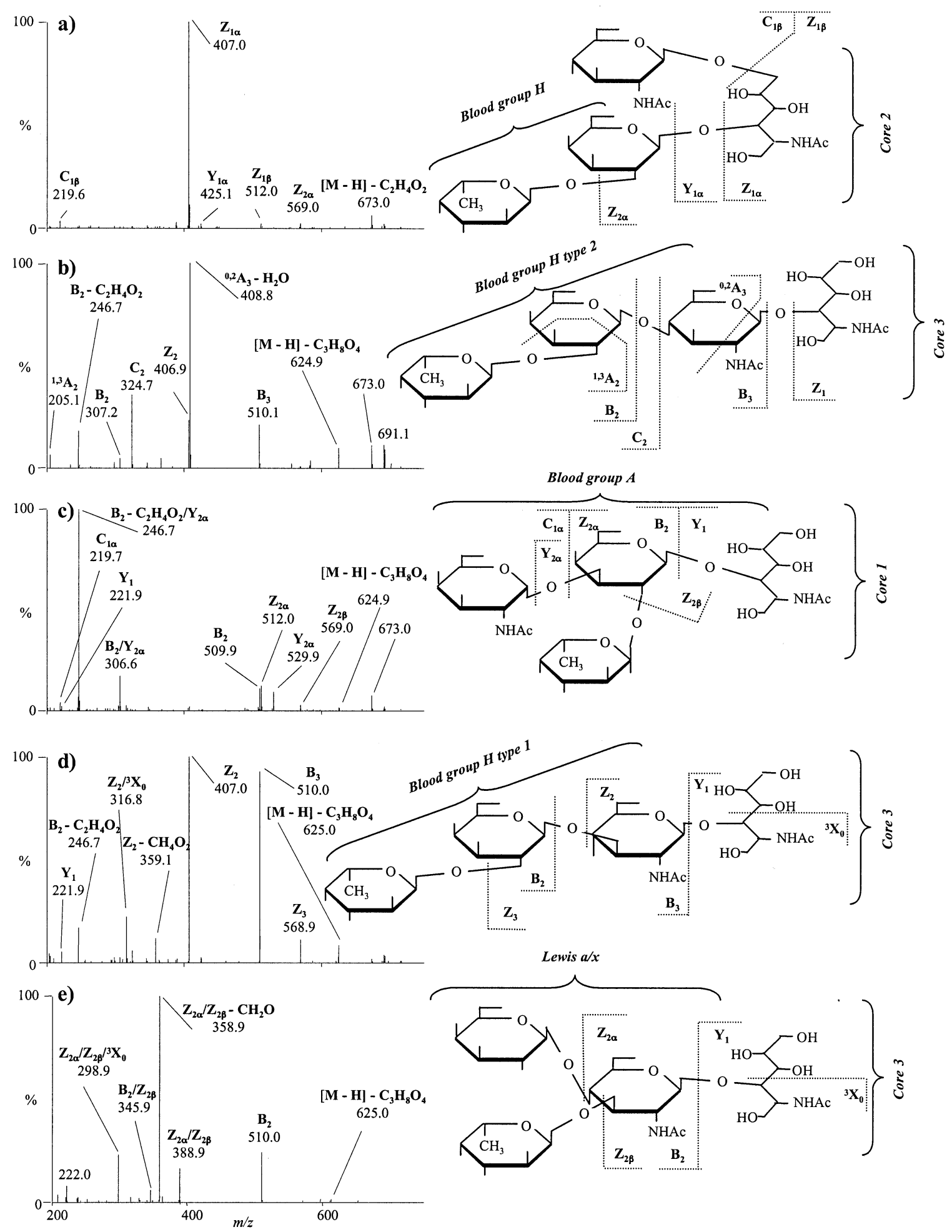

Figure 2. LC-MS ${ }^{2}$ spectra and assigned structures of isomeric oligosaccharides with $[\mathrm{M}-\mathrm{H}]^{-}$ion of $m / z 733$ corresponding to $\left[\mathrm{dHex}_{1} \mathrm{Hex}_{1} \mathrm{HexNAc}_{1} \mathrm{HexNAcol}_{1}\right]$ isolated from human MUC5B (a) retention time 22.6, (b) retention time 18.3, (d) retention time 15.8, and (e) retention time 10.9 and isolated from porcine gastric mucins (c) retention time 16.2.

composition $\mathrm{dHex}_{1} \mathrm{Hex}_{1} \mathrm{HexNAc}_{1} \mathrm{HexNAcol}_{1}$ ([M $\mathrm{H}]^{-}$ions of $\mathrm{m} / \mathrm{z}$ 733) illustrate that different specific complex fragmentation patterns can be obtained for tetrasaccharides with the same composition. Assigning fragment ions from the tetrasaccharide collision spectra showed that differences are related to the structural 
features of the oligosaccharides. Fragment ions were shown to correspond both to cleavages in the glycosidic bond $\left(\mathrm{B}_{i}\right.$ and $\mathrm{C}_{i}$ for non-reducing end fragments and $\mathrm{Y}_{i}$ and $Z_{i}$ for the reducing end), and some cross ring cleavages $\left(\mathrm{A}_{i}\right.$ and $\left.\mathrm{X}_{i}\right)($ nomenclature according to Domon and Costello [23]). Both single event cleavages and internal fragments were seen. Also, some odd fragment ions were detected like $[\mathrm{M}-\mathrm{H}]^{-}-\mathrm{C}_{3} \mathrm{H}_{8} \mathrm{O}_{4}, \mathrm{~B}_{2}-$ $\mathrm{C}_{2} \mathrm{H}_{4} \mathrm{O}_{2}$, and $\mathrm{Z}_{2}-\mathrm{CH}_{4} \mathrm{O}_{2}$ (Figure 2). These ions together with other specific fragment ions were further analyzed as described later on in the text. The knowledge obtained from fragmentation of small oligosaccharides was used for interpreting spectra of larger and more complex structures. In Figure 3 it is shown that the branching pattern can be determined for four different spectra of Core 4 hexasaccharides with the same composition $\mathrm{dHex}_{1} \mathrm{Hex}_{2} \mathrm{HexNAc}_{2} \mathrm{HexNAcol}_{1}$ ([M $\mathrm{H}]^{-}$ions of $m / z$ 1098) and in Figure 4 the spectra illustrate how the $\mathrm{ABO}-$ phenotype of human individuals are reflected on MUC5B Core 2 structures of deca- or nona-saccharides. In general, accompanying the intense glycosidic cleavages in all spectra were less intense fragments corresponding to loss of $42 \mathrm{u}\left(\mathrm{C}_{2} \mathrm{H}_{2} \mathrm{O}\right)$ or $60 \mathrm{u}$ $\left(\mathrm{C}_{2} \mathrm{H}_{4} \mathrm{O}_{2}\right.$ ) (for example $\mathrm{m} / \mathrm{z}$ 876.1, $\mathrm{m} / \mathrm{z} 673.1$, and $\mathrm{m} / \mathrm{z}$ 527.1 Figure 3) that could arise either from cross-ring cleavages and/or full or partial loss of side groups.

\section{Fragmentation of Core 1 (Galß1-3GalNAcol) and Core 3 (GlcNAcß1-3GalNAcol) Structures}

One of the most pronounced features found for mucin type O-linked oligosaccharide alditols with a singly C-3 substituted reducing terminus GalNAcol (Core 1 and Core 2) was the ion with a loss of $223 \mathrm{u}$ (from loss of the reducing end HexNAcol) from the pseudomolecular ion (resulting in $m / z 510$ in Figure $2 \mathrm{~b}-\mathrm{e}$ and $\mathrm{m} / \mathrm{z} 307$ in Figure $5 b$ ). This $B$ type ion could usually be seen above $10 \%$ intensity relative to the base peak in $\mathrm{MS}^{2}$-spectra of low molecular mass oligosaccharide Core 1 and Core 3 structures (Figure 2b-e and Figure 5b), but its intensity decreased as the size of the oligosaccharide increased. Core 1 and Core 3 containing structures also consistently showed an additional characteristic ion, the loss of $108 \mathrm{u}\left(\mathrm{C}_{3} \mathrm{H}_{8} \mathrm{O}_{4}\right)$ from the $[\mathrm{M}-\mathrm{H}]^{-}$ion (resulting in $m / z 625$ in Figure $2 b-e$ and $m / z 422$ in Figure $5 b$ ). This was believed to be due to fragmentation within the GalNAcol moiety, but further $\mathrm{MS}^{3}$ fragmentation of this ion did not yield more information about this fragment, since no additional cleavages within GalNAcol could be found in the $\mathrm{MS}^{3}$-spectrum (data not shown). A second approach to determine the origin of this $108 \mathrm{u}$ loss was devised where oligosaccharides were reduced by sodium borodeuteride instead of borohydride. This increases the mass of the reducing end monosaccharide unit by $1 \mathrm{u}$ and accordingly increases the mass of all fragment ions containing the deuterated $\mathrm{C}-1$ of the GalNAcol. To obtain high quality $\mathrm{MS}^{2}$ spectra from a Core 1 type structure, oligosaccharides from porcine gastric mucins were released in the presence of sodium borohydride or sodium borodeuteride and introduced to the MS source by direct infusion. The pseudomolecular ions $(\mathrm{m} / \mathrm{z} 530$ and 531 , respectively) corresponding to the non-deuterated and deuterated structure dHex12Hex1-3HexNAcol were chosen for collision (Figure 5). It was shown that the $[\mathrm{M}-\mathrm{H}]^{-}-\mathrm{C}_{3} \mathrm{H}_{8} \mathrm{O}_{4}(-108 \mathrm{u})$ fragment ion included the $\mathrm{C}-1$ of the GalNAcol, since the deuterated sample showed a fragment ion of $\mathrm{m} / \mathrm{z}$ 423.0 while the non-deuterated sample gave $\mathrm{m} / \mathrm{z} 422.1$. It was thus possible to narrow down the possibilities for the identity of this fragment ion, concluding that it could be derived from either the loss of C-4, C-5, and C-6 of the GalNAcol or alternatively a fragment losing C- 6 together with the acetyl group on the amide on C-2 (Figure 5). The $[\mathrm{M}-\mathrm{H}]^{-}-108$ fragment ion was never found in structures with substitution on both C-3 and C- 6 of the GalNAcol (i.e., Core 2 and Core 4 structures, see for example Figure 2a), nor could it be observed when only the C-6 was elongated (unpublished data).

One observation that cannot be easily explained is that low molecular weight Core 1 and Core 3 structures (up to trisaccharides) usually gave intense $\mathrm{Y}_{1^{-}}$or $\mathrm{Z}_{1^{-}}$fragment ions (only the reducing terminus GalNAcol), while larger structures gave less intense GalNAcol fragments $(<10 \%)$. This coincided with a shift from that the $Z_{1}$ fragment ion being the more intense towards that the $Y_{1}$ fragment ion becoming the more intense of the two as seen by comparing Figure $5 b\left(Z_{1}\right.$ ion of $\left.m / z 203.9\right)$ with Figure $2 \mathrm{c}-\mathrm{e}\left(\mathrm{Y}_{1}\right.$ ion of $\left.\mathrm{m} / \mathrm{z} 222.0\right)$.

\section{Fragmentation of Core 2 (Galß1-3(GlcNAc $\beta 1$ - 6) GalNAcol) and Core 4 (GlcNAc $\beta 1$ - 3)(GlcNAcß1-6)GalNAcol) Structures}

By far the most common extensions of the reducing terminal GalNAcol are structures with both a C-3 and a C-6-branch (Core 2 and Core 4 structures). This is also the case for the MUC5B oligosaccharides described in Table 1. Characteristic MS $^{2}$ fragmentation is exemplified for Core 2 in Figure 2a, Figure 4, and Figure 6a and for Core 4 in Figure 3. In order to determine which substituents are attached to which branch of GalNAcol, it is important to understand the fragmentation of the linear GalNAcol. It has previously been reported that a cleavage of the GalNAcol between C-4 and C-5 (designated as an ${ }^{4} \mathrm{~A}_{i}$ cleavage in this report) reveals the composition of the substituent on C-6 [14]. This cleavage was also found to occur in the structures described in this paper. In order to confirm the identity of this ${ }^{4} \mathrm{~A}_{4 \beta}$ fragment ion on a Core 2 structure, an $\mathrm{MS}^{3}$ experiment was carried out using the intense $[\mathrm{M}-\mathrm{H}]^{-}$ ion of $\mathrm{m} / \mathrm{z} 1041$ from Muc2 oligosaccharides released from rat small intestine [22] (Figure 6). This parent mass corresponds to a blood group H structure with Fuc $\alpha 1-$ $2 \mathrm{Gal} \beta 1$ - on the C-3 branch of GalNAcol and Fuc $\alpha 1$ $2 \mathrm{Gal} \beta 1-4 \mathrm{GlcNAc} \beta 1$ - on the C-6 branch. The collision spectra (Figure $6 \mathrm{~b}$ ) of the ${ }^{4} \mathrm{~A}_{4 \alpha}$ fragment ion $(\mathrm{m} / \mathrm{z} 570.1)$ 

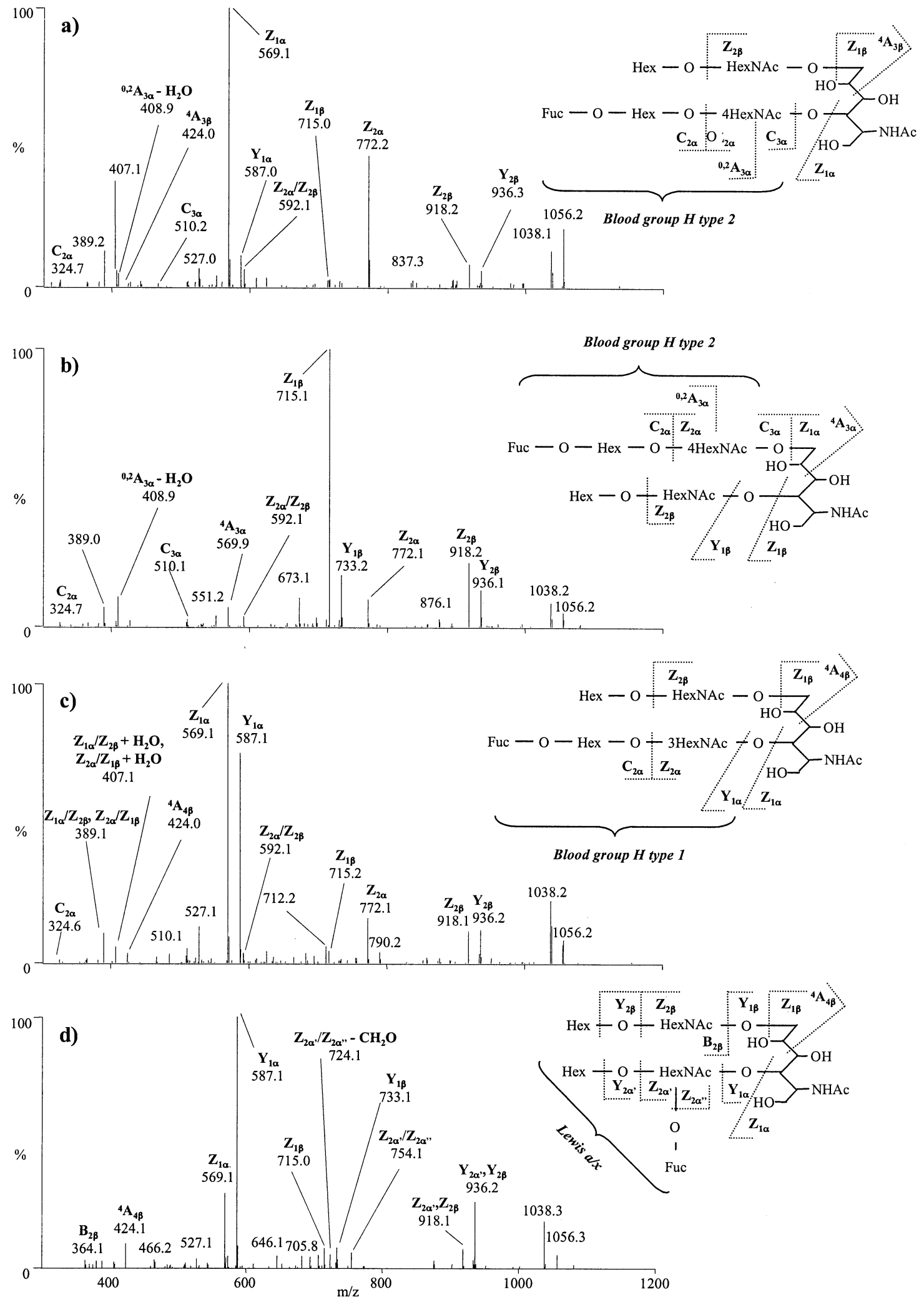

Figure 3. LC-MS ${ }^{2}$ spectra and assigned structures of isomeric Core 4 O-linked oligosaccharides with $[\mathrm{M}-\mathrm{H}]^{-}$ion of $\mathrm{m} / \mathrm{z} 1098$ corresponding to $\mathrm{dHex}_{1} \mathrm{Hex}_{2} \mathrm{HexNAc}_{2} \mathrm{HexNAcol}_{1}$ isolated from human MUC5B (a) retention time 19.1, (b) retention time 18.1, (c) retention time 16.2, and (d) retention time 14.9. 

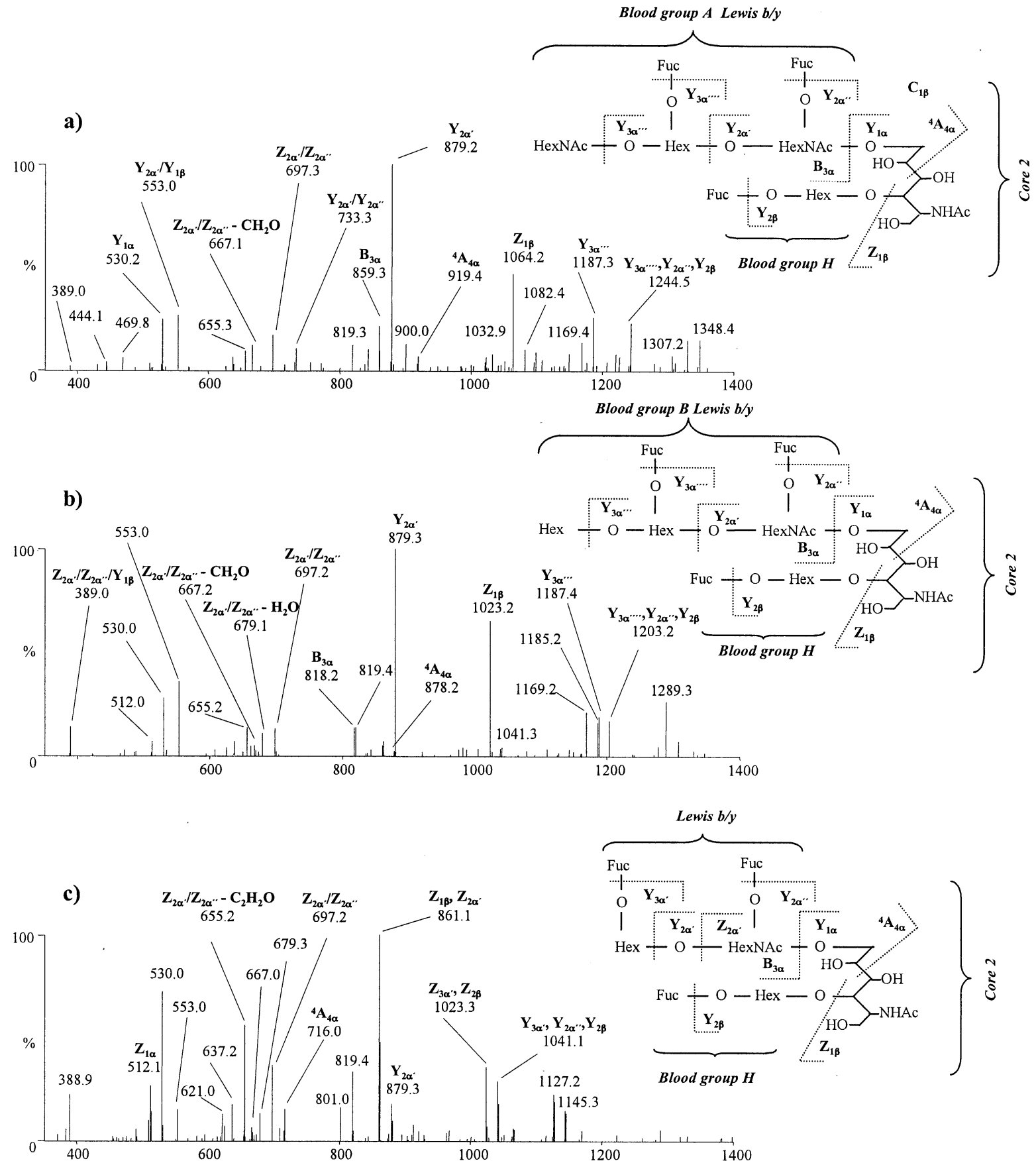

Figure 4. LC-MS ${ }^{2}$ of blood group determinant extended Lewis $\mathrm{b} / \mathrm{y}$ containing oligosaccharides on Core 2 O-linked oligosaccharides. (a) Oligosaccharide containing a blood group A structure (GalNAc $\alpha 1-3$ (Fuc $\alpha 1-2)$ Gal $\beta 1-$ ) on the C-6 branch of GalNAcol with a $[\mathrm{M}-\mathrm{H}]^{-}$ion of $m / z$ 1390. (b) Similar structure with a blood group B (Gal $\alpha 1-3$ (Fuc $\alpha 1-2)$ Gal $\beta 1-)$ with a $[\mathrm{M}-\mathrm{H}]^{-}$ion of $m / z$ 1349. (c) Similar blood group $\mathrm{H}$ structure without A or B extension with a $[\mathrm{M}-\mathrm{H}]^{-}$ion of $m / z 1187$.

was consistent with a Fuc $\alpha 1-2 \mathrm{Gal} \beta 1-4 \mathrm{GlcNAc} \beta 1$-chain with the addition of C-5 and C-6 of the GalNAcol, thus confirming the fragmentation between C-4 and C-5 of a GalNAcol substituted on C-6. The fragment is described here in its enol form with a double bound between C-5 and $\mathrm{C}-6$, but there is also the possibility that the fragment exists in its aldehyde form, or that the observed fragment ion is a mixture of both.
In all the $\mathrm{MS}^{2}$-spectra analyzed it was found that cleavage of the glycosidic linkage between C-3 of the GalNAcol and its extension gave intense reducing end fragmentation. $\mathrm{MS}^{2}$ of Core 2 oligosaccharides always gave $Z_{i}$ fragment ions from the GalNAcol C-3 branch cleavages among the most intense in the spectrum (e.g., Figure 6a). The fragment ions from cleavage of the equivalent glycosidic bond of Core 4 oligosaccharides 
a)

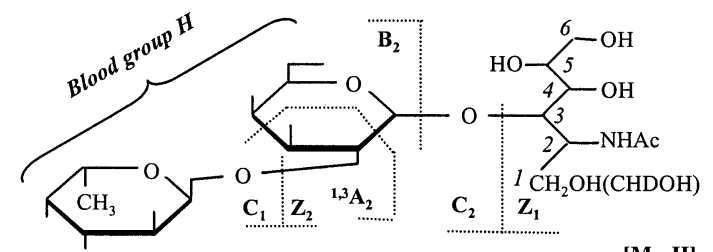

b)

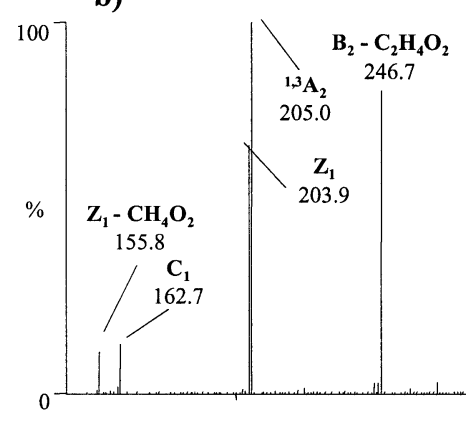

c)

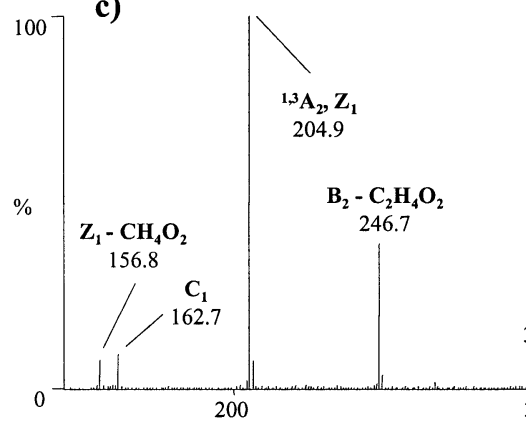

$[\mathrm{M}-\mathrm{H}]-\mathrm{C}_{3} \mathrm{H}_{8} \mathrm{O}_{4}$

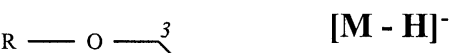

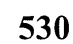

Figure 5. (a) Assigned fragmentation and $\mathrm{MS}^{2}$-spectra of dHex-2Hex-3HexNAcol reduced by (b) sodium borohydride or with (c) sodium borodeuteride. Samples introduced by direct infusion.

were also among the top intensity ions, but the type $\left(\mathrm{Y}_{i}\right.$ or $\mathrm{Z}_{i}$ fragmentation) depended on the type of additional elongation.

\section{Elongation of the Oligosaccharide by Type 1

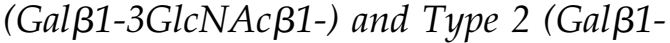 4 GlcNAc $\beta 1-)$ Chains}

While most of the intense ions for sequence information by $\mathrm{MS}^{2}$ are obtained by intense reducing end glycosidic cleavages, the mucin oligosaccharide Type 2 chain has been shown to give a specific ${ }^{0,2} \mathrm{~A}_{i}$ cleavage of the 4 substituted GlcNAc [14]. In small Type 2 elongated Core 3 structure this fragment $(\mathrm{m} / \mathrm{z} 408.8)$ dominates the spectrum (Figure $2 b$ ), but in more complex structures it is of lower intensity (5-10\%) (Figure $3 a-b$ and Figure 6a). By further fragmentation with $\mathrm{MS}^{3}$ of this ion (Figure 6c) it was shown that water from the ${ }^{0,2} \mathrm{~A}_{3 \beta}$ cleavage is eliminated from the remnant of the GlcNAc. This enabled us to propose a structure of the ${ }^{0,2} \mathrm{~A}_{3 \beta}-$ $\mathrm{H}_{2} \mathrm{O}$ fragment ion where the GlcNAc moiety is converted into an enone type structure as described in the Figure $6 \mathrm{c}$. The $\mathrm{MS}^{3}$ fragments that are derived from the ${ }^{0,2} \mathrm{~A}_{3 \beta}-\mathrm{H}_{2} \mathrm{O}$ fragment ion of $m / z 409$ are all directed towards the reducing end, indicating that the charge of the fragment is not held by the formed enone structure, but rather kept at other sites of the molecule.

While there was no single ion that was diagnostic for Type 1 structures, there were other features in the $\mathrm{MS}^{2}$ spectra that could be used for deducing their presence of Type 1 elongation. Using the absence of ${ }^{0,2} \mathrm{~A}_{i}-\mathrm{H}_{2} \mathrm{O}$ fragment ions as indicative of Type 1 structures it was discovered that the C-3 glycosidic cleavages of the GalNAcol of Core 2 and Core 4 structures gave almost equal intensity of the $Y_{i}$ - and $Z_{i}$-cleavages if a Type 1 sequence was directly attached to the C-3 (exemplified in Figure 3c), while attachment of Type 2 structures gave predominantly $Z_{i}$ type cleavage (Figure $3 a$ ).

Fucosylated Terminal Structures, Lewis $a / x$

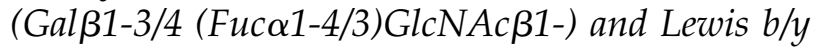

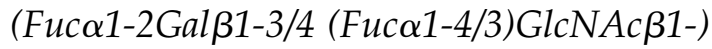

The presence of a C-3 and C-4 doubly substituted GlcNAc gave rise to some unusual $\mathrm{MS}^{2}$-fragmentation (Figure 2e). It was found that the two substituents on GlcNAc eliminated in what looked like a simultaneous event. We speculated on the formation of a conjugated 


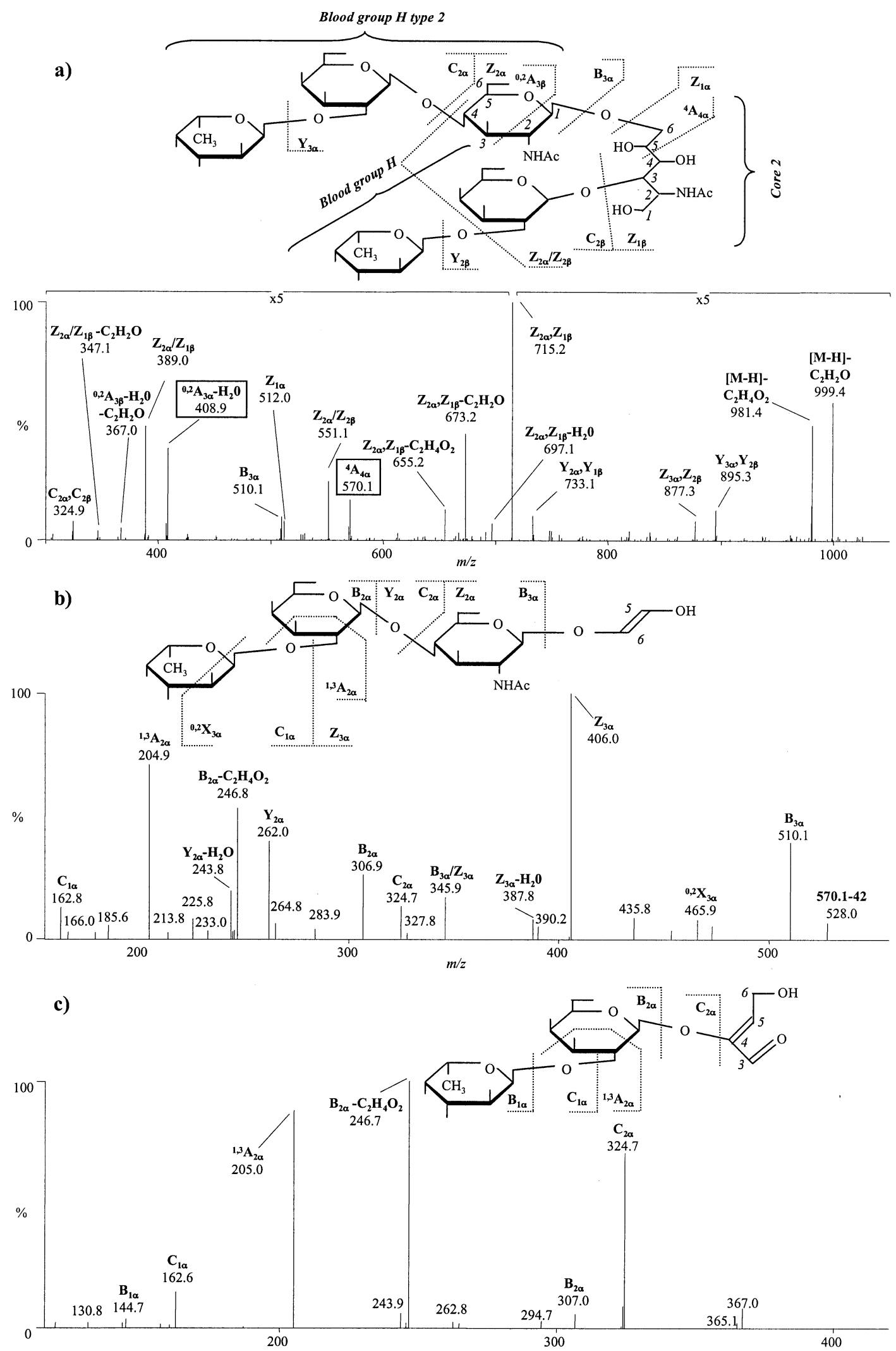

Figure 6. Assigned fragmentation and collision-spectra of dHex-2Hex-3(dHex-2Hex-4HexNAc6)HexNAcol from rat small intestine Muc2. (a) $\mathrm{MS}^{2}$-spectrum of the $[\mathrm{M}-\mathrm{H}]^{-}$ion of $\mathrm{m} / \mathrm{z} 1041$, (b) $\mathrm{MS}^{3}$-spectrum of the fragment ion of $m / z 570.1\left({ }^{4} \mathrm{~A}_{4 \alpha}\right.$ fragment for identification of the GalNAcol C-6 branch), and (c) $\mathrm{MS}^{3}$-spectrum of the fragment ion of $\mathrm{m} / \mathrm{z} 408.9\left[{ }^{0,2} \mathrm{~A}_{3 \beta}-\mathrm{H}_{2} \mathrm{O}\right.$ fragment for identification of the Type 2 chain (Gal $\beta 1-4 \mathrm{GlcNAc} \beta 1-)]$. Sample introduced by direct infusion. 


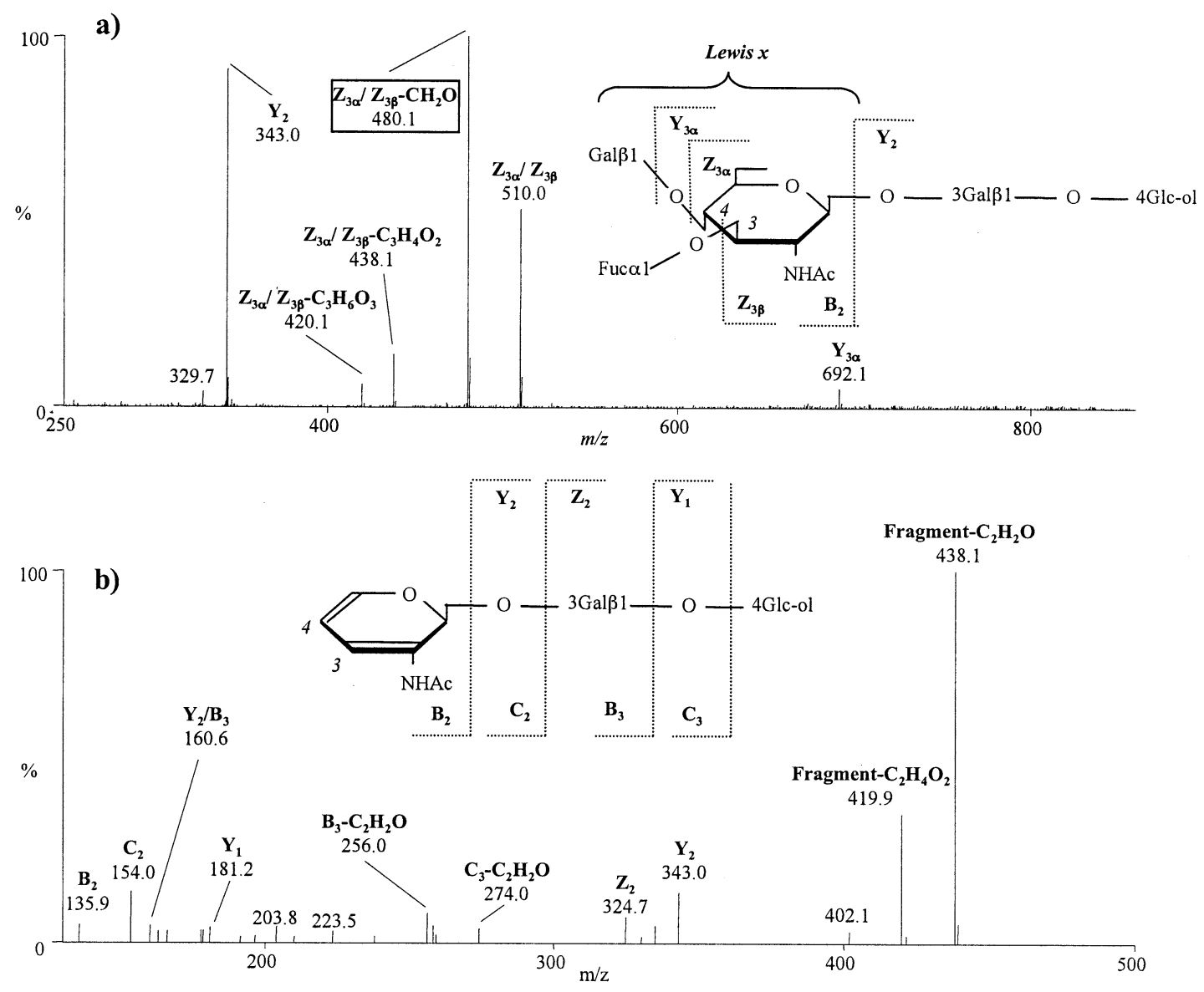

Figure 7. Assigned fragmentation and collision-spectra of LNFP III-alditol (Gal $\beta 1-4$ (Fuc $\alpha 1-3)$ GlcNAc $\beta 1$-3Gal $\beta 1$-4Glc-ol). (a) $\mathrm{MS}^{2}$-spectrum of the $[\mathrm{M}-\mathrm{H}]^{-}$ion of $m / z 854$ and (b) $\mathrm{MS}^{3}$-spectrum of the fragment ion of $m / z 480.1\left(\mathrm{Z}_{3 \alpha} / \mathrm{Z}_{3 \beta}-\mathrm{CH}_{2} \mathrm{O}\right)$ fragment for identification of a C-3 and C-4 disubstituted GlcNAc. Sample introduced by direct infusion.

diene product formed by dual elimination on the GlcNAc residue. The fragmentation observed suggested that the formation of a diene product could proceed by elimination of the C-3 and C-4 substituents of the GlcNAc and the proton on $\mathrm{C}-2$ and either the C-5 proton (the $Z_{i} / Z_{i}$ fragment ion in Figure 2e, Figure $3 d$, and Figure 7a), or the carbon-carbon bond between C-5 and $\mathrm{C}-6$ (the $\mathrm{Z}_{i} / \mathrm{Z}_{i}-\mathrm{CH}_{2} \mathrm{O}$ fragment in the same figures). This latter fragment was detected $30 \mathrm{u}$ lower than the $Z_{i} / Z_{i}$ ion. The hypothesis of a diene formation was tested using the reduced Lewis a/x containing milk oligosaccharide standards LNFP II (Gal $\beta 1-3$ (Fuc $\alpha 1$ 4)GlcNAc $\beta 1-3 \mathrm{Gal} \beta 1-4 \mathrm{Glc}-\mathrm{ol})$ ( $\mathrm{MS}^{2}$ - spectra not shown) and LNFP III (Gal $\beta 1-4$ (Fuc $\alpha 1-3)$ GlcNAc $\beta 1-3 G a l \beta 1-$ 4Glc-ol) (Figure 7). Collision induced dissociation of these two structures gave almost identical fragmentation in negative mode, where only minor differences in intensity of detected fragment ions could be seen. This indicates that it will be difficult to differentiate between Lewis a and Lewis $x$ by negative ion fragmentation.

Both LNFP II and LNFP III gave intense fragment ions due to the diene formation of the 3,4-substituted
GlcNAc. Further fragmentation of the $\mathrm{Z}_{i} / \mathrm{Z}_{i}-\mathrm{CH}_{2} \mathrm{O}$ ion in $\mathrm{MS}^{3}$, gave fragments both from the reducing end and the non-reducing end that confirmed for the presence of a GlcNAc-diene at the non-reducing end (Figure 7b showing LNFP III). This included the $\mathrm{B}_{2}(\mathrm{~m} / \mathrm{z}$ 135.9) and $C_{2}(m / z 154.0)$ ions, which are fragments consisting of only the GlcNAc diene and the $Y_{2}(\mathrm{~m} / \mathrm{z} 343.0)$ and $Z_{2}$ $(\mathrm{m} / \mathrm{z}$ 324.7) showing the single loss of a GlcNAc diene from the parent ion. Both reducing and non-reducing fragments were observed in the $\mathrm{MS}^{3}$ spectrum of LNFP III. This indicates that the localization of the charge within the parent ion does not contribute to the formation of the diene. Hence, charge remote fragmentation appears to be one pathway for the formation of this fragment.

The extension of the Lewis a and Lewis $x$ epitopes into Lewis $b$ and Lewis y epitopes with a Fuc $\alpha 1-2$ linked to the non-reducing end galactose was shown not to inhibit the formation of the diene (Figure 4c), but as the oligosaccharide extended the intensity of the diene fragments $\left(Z_{i} / Z_{i}\right.$ fragments) decreased. These fragment formations were also accompanied by the loss 
of acetyl and acetate from parts of the parent ion other than the disubstituted GlcNAc $(\mathrm{m} / \mathrm{z} 655.2$ and $\mathrm{m} / \mathrm{z} 637.2$ Figure 4c).

Since the diene was diagnostic for a C-3 and C-4 disubstituted GlcNAc, it was not possible to determine which of these was the attachment site for Gal $\beta 1$ - and Fuc $\alpha 1$ - of this GlcNAc in the structures found on the salivary MUC5B Lewis type oligosaccharides (Table 1). In one case, two isomers were found (retention time $13.4 \mathrm{~min}$ and $15.3 \mathrm{~min}$, respectively) with the same indistinguishable sequence and linkage information $\left([\mathrm{M}-\mathrm{H}]^{-}\right.$ion of $m / z 879$ with the sequence Fuc-Hex3/4(Fuc-3/4)HexNAc-3HexNAcol). An obvious explanation for the presence of these two isomers is a Lewis b structure (Fuca1-2Gal $\beta 1-3$ (Fuc $\alpha 1-4)$ GlcNAc $\beta 1-3 G a l-$ NAcol) and a Lewis y structure (Fuca1-2Gal $\beta 1-4$ (Fuc $\alpha 1-$ 3)GlcNAc $\beta 1-3$ GalNAcol). Both Lewis $b$ and Lewis $y$ have been found in saliva [24]. The graphitized carbon chromatography has a tendency to retain Type 2 structures longer than Type 1 structures (Table 1). Hence, the Lewis y structure is probably the later eluting isomer.

\section{Fucosylated Terminal Structures, Blood Group $H$ (Fuc 1 1-2Galß1-), Blood Group A (Fuc $\alpha 1-$

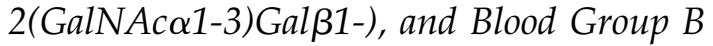 (Fuc $\alpha 1-2($ Gal $\alpha 1-3)$ Gal $\beta 1-)$}

In general, $Y_{i}$ and $Z_{i}$ cleavages produced by loss of terminal fucose were never found to be of high intensity $(<20 \%)$. This was particularly true for the Fuc $\alpha 1-2$ in the oligosaccharides with blood group H-determinants. The $Y_{i}$ - and $Z_{i}$-fragments that result from the cleavage of the disaccharide sequence of the Fuc $\alpha 1-2 \mathrm{Gal} \beta 1$ tended to be of higher intensity than from only cleavage of the single Fuc $\alpha 1-2$ (e.g., compare the $Z_{3}$ ion of $\mathrm{m} / \mathrm{z}$ 568.9 with $Z_{2}$ ion of $m / z 407.0$ in Figure $2 d$ ). Interestingly, blood group $\mathrm{H}$ Type 1 structures, but not $\mathrm{H}$ Type 2 structures, showed weak fragments from the GlcNAcdiene pathway, similar to Lewis type structures. However, the free hydroxyl on the C-4 of the GlcNAc in an $\mathrm{H}$ Type 1 structure (only C-3 extended) eliminated to a lesser extent than the Lewis type GlcNAc (C-3 and C-4 extended) (compare the $\mathrm{Z}_{2}-\mathrm{CH}_{4} \mathrm{O}_{2}$ fragment in Figure $2 \mathrm{~d}$ with the $\mathrm{Z}_{2 \alpha} / \mathrm{Z}_{2 \beta}-\mathrm{CH}_{2} \mathrm{O}$ fragment in Figure 2e).

Cross ring cleavages of blood group $\mathrm{H}$ determinants including the fucose and part of the galactose $\left({ }^{1,3} \mathrm{~A}_{2}\right.$ fragment) could be detected in the fragments of the smaller structures (e.g., $m / z 205$ in Figure $2 \mathrm{~b}$ and Figure $5 b)$, but this could not be used to non-ambiguously assign the fucose to the $\mathrm{C}-2$ of galactose, without further confirmation with other linkage isomers. Non-reducing end blood group H-determinant fragments also included weak $\mathrm{B}_{2}$ - and $\mathrm{C}_{2}$-cleavages (e.g., $\mathrm{m} / \mathrm{z} 306.9$ and $\mathrm{m} / \mathrm{z} 324.8$ in Figure $5 \mathrm{~b}$ ). These fragments could be accompanied with additional loss (e.g., $\mathrm{B}_{2}-\mathrm{C}_{2} \mathrm{H}_{4} \mathrm{O}_{2}$ of $\mathrm{m} / \mathrm{z} 246.7$ in Figure $2 \mathrm{~b}, \mathrm{~d}$, and Figure $5 \mathrm{~b}$ ). Fragmentation of blood group H-containing oligosaccharide alditol standards showed that this particular fragment was indicative for C-2 substituted galactose (data not shown), but the exact origin of the fragment could not be determined.

The majority of structures in this report were from a blood group $\mathrm{O}$ (or blood group $\mathrm{H}$ ) individual. Hence, it was not expected that blood group A or B containing structures would be found among the detected structures. To gain insight into these kinds of epitopes, oligosaccharides were analyzed from other sources. Oligosaccharides from MUC5B from one blood group $\mathrm{A} / \mathrm{B}$ individual and one blood group $\mathrm{A}$ individual were isolated as well as porcine gastric mucin oligosaccharides. While the two former samples were shown to be dominated by more Lewis $b / y$ containing structures extended into blood group A and B structures (exemplified in Figure 4), porcine gastric mucins contained fewer and shorter structures (exemplified in Figure 2c). A number of these structures were thoroughly analyzed, and it could be concluded that fragmentation of a C-3 and C-2 substituted Gal (Figure 2c) would not induce a diene formation, as was the case for a C-3 and C-4 substituted GlcNAc.

From the data set presented here it appears that no truly diagnostic cross ring fragments for the $\mathrm{ABO}$ type epitopes could be found. However, the presence of these epitopes can be suggested from the primary oligosaccharide sequence elucidated by the glycosidic cleavages using $\mathrm{MS}^{2}$ fragmentation. Linkage specific fragment ions from oligosaccharides containing Lewis $\mathrm{b} / \mathrm{y}$ extended with blood group A or B (GalNAc/ Gal $\alpha 1-3$ (Fuc $\alpha 1-2)$ Gal $\beta 1-3 / 4$ (Fuc $\alpha 1-4 / 3)$ GlcNAc $\beta 1-)$, could be more easily identified since $\mathrm{C}-3$ and $\mathrm{C}-4$ disubstituded GlcNAc gives characteristic $Z_{i} / Z_{i}$ fragment ions (Figure $4 \mathrm{a}$ and $\mathrm{b}$ ) (Table 3), similar to that described previously for Lewis $a / x$.

\section{Conclusions}

Informative $\mathrm{MS}^{2}$ spectra of neutral mucin type O-linked oligosaccharide alditols in negative ion mode were obtained, consisting mainly of reducing end fragment ions. The core type was predicted from the first daughter ion spectrum together with the mode of elongation (Type 1 or 2 chains) and terminal epitopes such as Lewis $a / x$ and Lewis $b / y$ together with the ABO-blood group antigens were indicated. For obtaining information on the overall glycosylation of mucins, the terminal epitopes described here can also be detected sensitively with antibodies. However, there are few immunonological methods to obtain information about core type or elongation type, since these epitopes could be hidden, and generic antibodies are not available. Traditionally to obtain this information, extensive oligosaccharide structural characterization by methylation analysis or ${ }^{1} \mathrm{H}-\mathrm{NMR}$ would be necessary, requiring large amounts of purified material.

The linkage information from $\mathrm{MS}^{2}$ was based on either pattern (e.g., intensity of $Z_{i}$ - versus $Y_{i}$-fragment ions of GalNAcol C-3), or the presence or absence of 
Table 3. Fragmentation pattern observed for fragmentation of mucin type oligosaccharides

\begin{tabular}{|c|c|c|c|}
\hline Epitope & $\begin{array}{l}\text { C-3 cleavage of GalNAcol } \\
\text { Cleavage type (relative intensity) }\end{array}$ & $\begin{array}{l}\text { Diagnostic ions } \\
\text { Cleavage type (relative intensity) }\end{array}$ & Other features \\
\hline $\begin{array}{l}\text { Core } 1 \text { less than } 4 \\
\text { residues }\end{array}$ & $Z_{i}(50-100 \%)$ & $\begin{array}{l}{[\mathrm{M}-\mathrm{H}]^{-}-223(1-100 \%)} \\
{[\mathrm{M}-\mathrm{H}]^{-}-108(1-5 \%)}\end{array}$ & \\
\hline $\begin{array}{l}\text { Core } 1 \text { more than } \\
3 \text { residues }\end{array}$ & $\begin{array}{l}{[\mathrm{M}-\mathrm{H}]^{-}-223(1-10 \%)} \\
{[\mathrm{M}-\mathrm{H}]^{-}-108(1-5 \%)} \\
\mathrm{Z}_{i} \text { and } \mathrm{Y}(<10 \%)\end{array}$ & & \\
\hline Core 2 & $Z_{i}(50-100 \%)$ & $\begin{array}{l}{ }^{4} A_{i} \text {-cleavage of GalNAcol } \\
(1-20 \%)\end{array}$ & \\
\hline $\begin{array}{l}\text { Core } 3 \text { less than } \\
5 \text { residues }\end{array}$ & $Z_{i}(20-100 \%)$ & $\begin{array}{l}{[\mathrm{M}-\mathrm{H}]^{-}-223(1-100 \%)} \\
{[\mathrm{M}-\mathrm{H}]^{-}-108(1-5 \%)}\end{array}$ & \\
\hline Core 4 & $Z_{i} 50-100 \%, Y(5-35 \%)$ & $\begin{array}{l}{ }^{4} A_{i} \text {-cleavage of GalNAcol } \\
(1-20 \%)\end{array}$ & \\
\hline Type 1 & $\begin{array}{l}Z_{i} \text { and } Y_{i}(50-100 \%) \\
\text { Equal in size if type } 1 \text { on } C-3\end{array}$ & & \\
\hline Type 2 & $\begin{array}{l}\text { Mostly } Z_{i}(50-100 \%) \\
\quad \text { if type } 2 \text { branch on C-3 }\end{array}$ & $\begin{array}{l}{ }^{0,2} \mathrm{~A}_{i}-\mathrm{H}_{2} \mathrm{O} \text { cleavage of GlcNAc } \\
(2-100 \%)\end{array}$ & \\
\hline Lewis $a / x$ & $\begin{array}{l}\text { Mostly } Y_{i}(50-100 \%) \\
\text { if epitope on C-3 }\end{array}$ & $\begin{array}{l}{[\mathrm{M}-\mathrm{H}]^{-}-344 \text { and }} \\
{[\mathrm{M}-\mathrm{H}]^{-}-374\left(\mathrm{Z}_{i} / \mathrm{Z}_{i} \text { cleavages }\right)} \\
\quad(5-100 \%)\end{array}$ & loss of Gal $\beta 1-3 / 4$ mostly $Y_{i}(<10 \%)$ \\
\hline Lewis $y / b$ & $\begin{array}{l}\text { Mostly } Y_{i}(50-100 \%) \\
\text { if epitope on C-3 }\end{array}$ & $\begin{array}{l}{[\mathrm{M}-\mathrm{H}]^{-}-490 \text { and }} \\
{[\mathrm{M}-\mathrm{H}]^{-}-520\left(\mathrm{Z} / \mathrm{Z}_{i} \text { cleavages }\right)} \\
\quad(5-100 \%)\end{array}$ & $\begin{array}{l}\text { loss of Fuc } \alpha 1-3 / 4(<2 \%) \\
\text { loss of Fuc } \alpha 1-2 / 3 / 4(<10 \%)\end{array}$ \\
\hline Blood group $\mathrm{H}$ & & $\begin{array}{l}\text { Lewis } \mathrm{y} / \mathrm{b} \text { gives }[\mathrm{M}-\mathrm{H}]^{-}-490 \\
\quad \text { and }[\mathrm{M}-\mathrm{H}]^{-}-520 \\
\left(\mathrm{Z}_{i} / \mathrm{Z}_{i} \text { cleavages }\right)(5-100 \%)\end{array}$ & loss of Fuc $\alpha 1-2$ mostly $Y_{i}(<10 \%)$ \\
\hline Blood group $A / B$ & & $\begin{array}{l}\text { A Lewis } \mathrm{y} / \mathrm{b} \text { gives }[\mathrm{M}-\mathrm{H}]^{-} \\
-693 \text { and }[\mathrm{M}-\mathrm{H}]^{-}-723 \\
\left(\mathrm{Z} / \mathrm{Z}_{i} \text { cleavages }\right)(5-100 \%) \\
\text { B Lewis y/b gives }[\mathrm{M}-\mathrm{H}]^{-} \\
-652 \text { and }[\mathrm{M}-\mathrm{H}]^{-}-682 \\
\left(\mathrm{Z}_{i} / \mathrm{Z}_{i} \text { cleavages }\right)(5-100 \%)\end{array}$ & $\begin{array}{l}\text { loss of Gal } \alpha 1-3 \text { or GalNAc } \alpha 1-3 Y_{i} \\
\text { and } Z_{i}(<20 \%)\end{array}$ \\
\hline
\end{tabular}

characteristic ions. In particular, these were the [M $\mathrm{H}]^{-}-\mathrm{C}_{3} \mathrm{H}_{8} \mathrm{O}_{4}$ fragment ion diagnostic for Core 1 and Core 3 , the ${ }^{4} \mathrm{~A}_{i}$ fragment ion indicative of the C-6 extension on GalNAcol (Core 2 and Core4), the ${ }^{0,2} \mathrm{~A}_{i}-$ $\mathrm{H}_{2} \mathrm{O}$ fragment ion for Type 2 chains and the $\mathrm{Z}_{i} / \mathrm{Z}_{i}$ double cleavage fragment ions from $C-3$ and $C-4$ disubstituted GlcNAc (Table 3). The identities of these predicted fragments were verified by $\mathrm{MS}^{3}$ or isotopic labeling. The applicability of this approach for analyzing mucin oligosaccharides was illustrated with the structural identification of 50 different neutral oligosaccharides from human salivary MUC5B (Table 1). The negative ion fragmentation of the neutral mucin oligosaccharide alditols was quite different from similar structures isolated from milk with a reducing end Glc instead of GalNAcol [10, 11, 25]. While the fragmentation of milk oligosaccharides is dominated by nonreducing end fragments, mucin oligosaccharide alditols give more reducing end fragments. This suggests that some of the diagnostic reducing end fragments described here will only be observed on oligosaccharide alditols. We have observed that the diene formation of Lewis type structures, as described here, will only occur on reduced
Lewis a/x containing LNFPII and LNFPIII oligosaccharides, but not with their reducing counterparts.

The amount of saliva used for LC-MS ${ }^{2}$ in any one experiment corresponded to $50 \mu \mathrm{L}$ of the total $5-10 \mathrm{~mL}$ starting material. The emphasis in this report was not the sensitivity, but rather to acquire enough fragmentation data in order to be able to distinguish general patterns and pathways. We have shown that this approach of characterizing oligosaccharides from mucins isolated by gel electrophoresis is applicable to even less material [14], and this report, describing a detailed $\mathrm{MS}^{2}$ fragmentation of mucin oligosaccharides, is a continuation of this work. The use of negative ion electrospray mass spectrometry is shown in this report to be able to provide substantial information on the structure of the oligosaccharides attached to proteins. Combined with the improvements in the isolation of glycoproteins, the release of the oligosaccharides and the separation of structural isomers by chromatography, the time needed for this type of analysis is being reduced. The bottleneck for higher throughput analysis of oligosaccharides is now at the level of the complex data analysis. This emphasizes the future need for good oligosaccharide 
databases, and intelligent bioinformatic tools to handle and interpret this data.

\section{References}

1. Harvey, D. J. Identification of Protein-Bound Carbohydrates by Mass Spectrometry. Proteomics 2001, 1, 311-328.

2. Dell, A.; Morris, H. R. Glycoprotein Structure Determination by Mass Spectrometry. Science 2001, 291, 2351-2356.

3. Reinhold, V. N.; Reinhold, B. B.; Costello, C. E. Carbohydrate Molecular Weight Profiling, Sequence, Linkage, and Branching Data: ES-MS and CID. Anal. Chem. 1995, 67, 1772-1784.

4. Mechref, Y.; Novotny, M. V. Structural Investigations of Glycoconjugates at High Sensitivity. Chem. Rev. 2002, 102, 321-369.

5. Costello, C. E. Bioanalytic Applications of Mass Spectrometry. Curr. Opin. Biotechnol. 1999, 10, 22-28.

6. Kui Wong, N.; Easton, R. L.; Panico, M.; Sutton-Smith, M.; Morrison, J. C.; Lattanzio, F. A.; Morris, H. R..; Clark, G. F.; Dell, A.; Patankar, M. S. Characterization of the Oligosaccharides Associated with the Human Ovarian Tumor Marker CA125. J. Biol.Chem. 2003, 278, 28619-28634.

7. Rudd, P. M.; Endo, T.; Colominas, C.; Groth, D.; Wheeler, S. F.; Harvey, D. J.; Wormald, M. R.; Serban, H.; Prusiner, S. B.; Kobata, A.; Dwek, R. A. Glycosylation Differences Between the Normal and Pathogenic Prion Protein Isoforms. Proc. Natl. Acad. Sci. U.S.A. 1999, 96, 13044-13049.

8. Karlsson, H.; Johansson, L.; Miller-Podraza, H.; Karlsson, K. A. Fingerprinting of Large Oligosaccharides Linked to Ceramide by Matrix-Assisted Laser Desorption/Ionization Time-of-Flight Mass Sspectrometry: Highly Heterogeneous Polyglycosylceramides of Human Erythrocytes with Receptor Activity for Helicobacter pylori. Glycobiology 1999, 9, 765-778.

9. Hofsteenge, J.; Muller, D. R.; de Beer, T.; Loffler, A.; Richter, W. J.; Vliegenthart, J. F. New Type of Linkage Between a Carbohydrate and a Protein: C-Glycosylation of a Specific Tryptophan Residue in Human RNase Us. Biochemistry 1994, 33, 13524-13530.

10. Chai, W.; Piskarev, V.; Lawson, A. M. Branching Pattern and Sequence Analysis of Underivatized Oligosaccharides by Combined MS/MS of Singly and Doubly Charged Molecular Ions in Negative-Ion Electrospray Mass Spectrometry. J. Am. Soc. Mass Spectrom. 2002, 13, 670-679.

11. Pfenninger, A.; Karas, M.; Finke, B.; Stahl, B. Structural Analysis of Underivatized Neutral Human Milk Oligosaccharides in the Negative Ion Mode by Nano-Electrospray MS(n). Part 1: Methodology. J. Am. Soc. Mass Spectrom 2002, 13, 1331-1340.
12. Thomsson, K. A.; Karlsson, H.; Hansson, G. C. Sequencing of Sulfated Oligosaccharides from Mucins by Liquid Chromatography and Electrospray Ionization Tandem Mass Spectrometry. Anal. Chem. 2000, 72, 4543-4549.

13. Kawasaki, N.; Ohta, M.; Hyuga, M.; Hayakawa, T. Application of Liquid Chromatography/Mass Spectrometry and Liquid Chromatography with Tandem Mass Spectrometry to the Analysis of the Site Specific Carbohydrate Heterogeneity in Erythropoietin. Anal. Biochem. 2000, 285, 82-92.

14. Schulz, B. L.; Packer, N. H.; Karlsson, N. G. Small-Scale Analysis of O-Linked Oligosaccharides from Glycoproteins and Mucins Separated by Gel Electrophoresis. Anal. Chem 2002, 74, 6088-6097.

15. Kannagi, R. Regulatory Roles of Carbohydrate Ligands for Selectins in the Homing of Lymphocytes. Curr. Opin. Struct. Biol. 2002, 12, 599-608.

16. Rosen, S. D.; Bertozzi, C. R. The Selectins and Their Ligands. Curr. Opin. Cell Biol 1994, 6, 663-673.

17. Gendler, S. J.; Spicer, A. P. Epithelial Mucin Genes. Annu. Rev. Physiol. 1995, 57, 607-634.

18. Ramphal, R.; Arora, S. K. Recognition of Mucin Components by Pseudomonas aeruginosa. Glycoconj. J 2001, 18, 709-713.

19. Linden, S.; Nordman, H.; Hedenbro, J.; Hurtig, M.; Borén, T.; Carlstedt, I. Strain- and Blood Group-Dependent Binding of Helicobacter pylori to Human Gastric MUC5AC Glycoforms. Gastroenterology 2002, 123, 1923-1930.

20. Evans, D. J., Jr.; Evans, D. G. Helicobacter pylori Adhesins: Review and Perspectives. Helicobacter 2000, 5, 183-195.

21. Thomsson, K. A.; Prakobphol, A.; Leffler, H.; Reddy, M. S.; Levine, M. J.; Fisher, S. J.; Hansson, G. C. The Salivary Mucin MG1 (MUC5B) Carries a Repertoire of Unique Oligosaccharides that is Large and Diverse. Glycobiology 2002, 12, 1-14.

22. Olson, F. J.; Johansson, M. E.; Klinga-Levan, K.; Bouhours, D.; Enerbäck, L.; Hansson, G. C.; Karlsson, N. G. Blood Group A Glycosyltransferase Occurring as Alleles with High Sequence Difference is Transiently Induced During a Nippostrongylus brasiliensis parasite infection. J. Biol. Chem. 2002, 277, 1504415052.

23. Domon, B.; Costello, C. E. A Systematic Nomenclature of Carbohydrate Fragmentation in FAB-MS/MS Spectra of Glycoconjugates. Glycoconj. J. 1988, 5, 397-409.

24. Klein, A.; Carnoy, C.; Wieruszeski, J. M.; Strecker, G.; Strang, A. M.; van Halbeek, H.; Roussel, P.; Lamblin, G. The Broad Fiversity of Neutral and Sialylated Oligosaccharides Derived from Human Salivary Mucins. Biochemistry 1992, 31, 61526165.

25. Chai, W.; Piskarev, V.; Lawson, A. M. Negative-Ion Electrospray Mass Spectrometry of Neutral Underivatized Oligosaccharides. Anal. Chem. 2001, 73, 651-657. 